\title{
A Contrastive Study of Metaphorical Expressions of $U p$ Sense Spatial Words in English and Chinese
}

\author{
He Pan \\ Tianjin University Renai College \\ Tianjin, China
}

\begin{abstract}
The present study makes an attempt to explore the metaphorical extensions of $U p$ sense spatial words from four aspects: quantity, state, time and social status, drawing on the theoretical framework of cognitive linguistics, concentrating on the conceptual metaphor theory by Lakoff and Johnson. From the viewpoint of the contemporary metaphorical theory, many of our fundamental concepts are structured through spatial metaphors rooted in our physical, social and cultural experiences. To testify this claim, this study collected data from two famous literature works: one is $A$ Dream of Red Mansions in Chinese and the other is Gone with the Wind in English. The data was analyzed from a crosslinguistic and a cross-cultural perspective and through qualitative and quantitative methods. The conclusion was made due to human beings' shared understandings and experience that there are remarkable similarities between English and Chinese metaphorical extensions of $U p$ and Shang. The findings support Lakoff and Johnson's conceptual metaphor theory, thus offering another linguistic evidence for the possible existence of a universal spatial metaphorical system, which are helpful to improve language teaching and learning and translation studies in Chinese and English since the present thesis is a contrastive study between the two languages.
\end{abstract}

Keywords—spatial metaphor; cognitive linguistics; mapping; Up; Shang

\section{INTRODUCTION}

The contemporary theory of metaphor claims that metaphorical thinking is part of the cognitive processes through which the human mind conceptualizes the world. To be specific, many of our fundamental concepts are structured through spatial metaphors, which are rooted in our physical, social and cultural experiences. Abstract concepts are at least in part understood and expressed metaphorically in spatial terms and that abstract reason is achieved by using certain mechanisms for the perception of spatial relations. This is seen as the consequence of the Invariance Principle, which states that metaphor projects the image-schematic structure of the source domain onto the target domain in a way that is consistent with inherent target domain structure. It casts the abstract and the nonphysical into the concrete and the physical, usually with spatial dimensions.

Vertical metaphors, as one kind of spatial metaphors, transfer meanings to abstract concepts through vertical relation words: $U p$ and Down. Drawing on the theoretical framework of cognitive linguistics and focusing on spatial metaphors, we are going to investigate the similarities and differences of the metaphorical use of $U p$ sense words in Chinese and English cognition and culture and to explore and prove Lakoff's conceptual metaphor theory in which spatial metaphors can be mapped into four dimensions: quantity, state, time and social status. The primary objective of the present study is to contribute to the conceptual metaphor theory and provide linguistic evidence to identify the hypothesis predicted by Johnson and Lakoff that there may be a possible existence of a universal spatial metaphorical system from a cross-linguistic and crosscultural perspective and through qualitative and quantitative methods.

\section{MethodOLOGY}

Aiming to provide linguistic evidence for the possible existence of the universal spatial metaphorical system from a cross-linguistic and cross-cultural perspective, so as to make contribution to the contemporary theory of metaphor, both qualitative and quantitative methods will be used for the comparative study.

Before collecting the data, an important point should be made clear that the capitalized letters SHANG and UP are abstract concepts. SHANG in Chinese include 上 (shang,up), 顶 (ding, top), 高 (gao, high), 立(li, stand up), 起 (qi, upwards), 升 (sheng, rise), 首 (shou, head), 提 (ti, pull), 头 (tou, head), etc. Up in English include up, above, ascend, jump, top, lift, raise, high, etc. In this study, one Chinese word, Shang and one English word, $U p$ will be taken as concrete data representing SHANG and $U P$ to show their metaphorical extensions. The data will be collected from the two famous literature works: one is the Chinese work A Dream of Red Mansions (containing 733,034 Chinese characters in total), the other is the English work Gone with the Wind (containing 422,177 English words in total). According to Modern Chinese Common Usage Words Frequency Dictionary, the most frequently used $U p$ sense spatial word is Shang. According to the 5 million words cobuild corpus, the most frequently used $U p$ sense spatial word is $U p$. Aiming to explore the metaphorical mapping of the $U p$ sense spatial words both in Chinese and English, sentences or expressions containing the most frequently used Chinese word Shang and the most frequently used English word $U p$ will be selected from the above two famous works. All the expressions and 
sentences including the two words Shang and $U p$ will be chosen as data of the study.

According to the meaning of Shang and $U p$ in specific contexts, all the sentences or expressions will be classified into several categories like spatial category, metaphorical category or other possible category. Quantitative study will further be made to draw the frequencies of the above categories in order to elaborate the metaphorical extensions of Shang and $U p$.

As a result, there come $U p 3815$ sentences containing the character Shang and 1530 sentences containing the word $U p$. As there are so many repetitive uses of Shang and $U p$, careful selection is needed in order to make sure that there are no repetitions. Among those data, 485 different sentences of Shang and 232 different sentences containing $U p$ are selected as samples of the study. Since all the data come from the fixed literature, meanings of sentences will be clearly comprehended through contextual understanding.

According to Langacker's TR-LM paradigm(Langacke 1987: 217), all the sentences containing Shang and Up will be considered carefully in order to determine that whether the two words are used as their originally spatial meanings, or mapped onto that four non-spatial target domains, or used in other conditions. The criteria for this categorization are to determine whether the certain metaphorical expression includes a mapping from a physical source domain to an abstract target domain. The metaphorical extensions of Shang and $U p$ will be in our major concern. As metaphor and culture are combined together, in the process of analyzing the cognitive models of Shang and $U p$, their cultural models will also be under consideration.

\section{Cognitive Analysis of $U P$ Sense Spatial WoRds BETWEEN ENGLISH AND CHINESE}

This chapter is about the spatial meaning of Shang and $U p$ and their metaphorical extensions as reflected in the two famous literary works A Dream of Red Mansions and Gone with the Wind. Shang and $U p$ originated as purely spatial concepts. Because of the importance of the space domain, and of $U p$ dimension in particular, together with human beings' bodily experiences, history, culture and society of these two languages speaking countries, these two concepts can be mapped from the original spatial domain onto other abstract domains.

\section{A. The Study of Shang in Chinese}

After consulting The Words Origin (Commercial Press, 1979), Ancient and Modern Chinese Dictionary (Shanghai Dictionary Press 1995), Xinhua Dictionary (Commercial Press, 2007), meanings of Shang can be classified into three groUps: vertical sense (墙上 on the wall), metaphorical sense (思想上 in thought) and horizontal sense (上街 go to the street).

According to the metaphorical sense, five conceptual metaphors can be abstracted:

- At/towards a Larger Quantity is Shang

- At/towards a More Important Status is Shang
- At/towards an Earlier Time is Shang

- At/towards a More Desirable States is Shang

- Expressing an Extent is Shang

That is to say, Shang can be mapped from vertical domain onto domains of quantity, social status and hierarchy, time, states and extent. People map the spatial relations onto those abstract domains so that the abstract concepts will be understood clearer and better.

1) Quantity: The conceptual metaphor of Quantity in terms of Shang is: At/towards a Larger Quantity is Shang. In this metaphor, the image schematic structure of the vertical word Shang is mapped onto the target domain of Quantity. The quantity of objects has close relationship with the vertical scale. The more a pile of objects are, the higher they will be. If you add more of a substance or of physical objects to a container or pile, the level goes $U p$. For example, when constructing a building, the adding of bricks will make the building higher and higher. This kind of activity occurs repetitively in our daily life so it becomes the physical basis for the above mentioned metaphor. In describing capital, price, value, and quantity of the commodities, the concept of Shang plays an important role. It makes the quantity relations in abstract economic development concrete. In stock market graphs, the increase of stock prices is represented as rising curve.

Examples from A Dream of Red Mansions are illustrated in the following:

亲上作亲, 娶的就是政老爹夫人王氏之内侄女, 今已娶了二年。 (Two years ago he married a relative, the niece of China Cheng's wife Lady Wang.)

但如今家内杂事太烦, 太太渐上了年纪, 一时想不到也是有的。 (But we've plenty of troublesome business here, and now that Her Ladyship's growing old she sometimes forgets things.)

From the above examples, it can be observed that within the target domain Quantity, there exist increase in closeness is Shang, increase in doing things is Shang.

2) Social status: The conceptual metaphor of Social Status in terms of Shang is: At/towards a More Important Status is Shang. The concrete word Shang is used to metaphorically refer to the social status and hierarchy. In human society, status and power are in direct proportion. The higher the status, the more powerful the man will be. High status is Shang: 皇上(Emperor), 上宾 (important guest).

China has long been a man dominant society. In thousands of years, China had been a feudal society with extremely strict hierarchy, which played a very important role in Chinese social life, political life even in daily activities. In such a hierarchical society, the emperor, enjoying a sovereign power, was above all the other people. Below the emperor, ministers were divided into different ranks and all of them should obey the emperor's order absolutely. Such a hierarchical system was so powerful that 
it even influenced the inner family structure. In a family, parents were at the top rank, and then sons and grandsons. The will of parents cannot be violated. Even in the modern society, status is closely related to power. The higher one's status is, the more power he has.

Examples from A Dream of Red Mansions are as follows:

上无亲母教养, 下无姊妹兄弟扶持。(You are young and delicate, with no mother to take care of you, no sisters or brothers to look after you.)

主仆上下, 安富尊荣者尽多, 运筹谋画者无一。(Masters and servants alike are so used to larding it in luxury that not one of them thinks ahead.)

3) Time: The conceptual metaphor of Time in terms of Shang is: At/towards an Earlier Time is Shang.

Studies have shown that the temporal concepts are resulted from the mapping from the space domain to the temporal domain. The image schematic structures of Shang are mapped from a concrete spatial domain onto the abstract intangible domain of time, making the latter understandable.

In the process of individual growth, the conception of spatial relations is acquired before those of temporal relations. According to Akhundov (1986: 21-22), although there are a great many temporal aspects in the life of the newborn, the child is late in acquiring a concept of time. This may be due to features of the evolutionary process, in which a sense of space precedes that of time. It can also be observed that, as the child attempts to conceptualize time, he or she actually operates with spatial relations for a considerable period. (Lan Chun 2003: 97) Chinese uses a different spatial axis for its source domain. In certain Chinese expressions, time flows from top to bottom. From the perspective of Chinese culture, people look upon tradition and cherish things in the past and always lost in past good memories. Looking from this point of view, Chinese regard the earlier time is Shang.

Examples from A Dream of Red Mansions are as follows:

(女孩们) 上一辈的(名字), 却也是从兄弟而来的。(But all the girls in the last generation had names like those of boys.)

我因业师上年回家去了, 也现荒废着呢。(My tutor went home last year, so I'm at a loose end myself for the time being.)

4) States: The conceptual metaphor of States in terms of Shang is: At/towards a More Desirable State is Shang.

Generally speaking, Shang is connected with good things. For example, high quality is Shang: 上乘(high quality), 上品 (high quality), 上计 (good idea), 上策 (good plan), 上好 (very good), 上上签(very good sign). The society is composed by human beings. Virtue is an acknowledged moral standard in the whole society. Persons with virtue are respected by others, so Virtue is Shang: 他是个正直的人.(He is an upright man.)

Examples from A Dream of Red Mansions are as follows:

a) Quality: Of Better Quality is Shang

薛姨妈便令人去灌了最上等的酒来. (His aunt (Aunt Hsueh) promptly sent for the best wine in the house.) b) Morality: Of/towards Higher Morality is Shang

今风尘碌碌, 一事无成, 忽念及当日所有之女子, 一一细考较去, 觉 其行止见识, 皆出于我之上. (In this busy, dusty world, having accomplished nothing, I suddenly recalled all the girls I had known, considering each in turn, and it dawned on me that all of them surpassed me in behavior and understanding.)

c) Active State: Into an Active State is Shang

气的是他兄弟不学好, 不上心念书, 以致如此学里吵闹. (He was upset because Chin Chung doesn't study hard or give his mind to his books, and that's how this trouble started.)

\section{d) Publicity: Towards Publicity is Shang}

因此上演出这怀金悼玉的《红楼梦》。(By singing this Dream of Red Mansions to mourn the Gold and the Jade.)

5) Extent: The conceptual metaphor of Extent in terms of Shang is: Expressing an Extent is Shang.

When people project this spatial position onto a mental space, that imaginary abstract space will be regarded as a something with surfaces. As a result, a concept of extent formed into being. E.g. 心上 (in heart),理论上(in theory). In the data collection, the concept of extent enjoys an important position. 50 instances are found to express Extent. Examples are as follows:

老先生倚门仁望, 敢是街市上有甚新闻否? (What are you watching from your gate, sir? Is there any news in town?)

宝玉只答应着, 也无心在饮食上, 只问秦钟近日家务等事。(Paoyu agreed but he had no interest in food, so eager was he to learn more about how his new friend (Chin Chung) lived.)

\section{B. Elaborations of Shang from Vertical to Horizontal Relations}

Apart from the five metaphorical extensions mentioned above, it is also found that there exists an elaboration from vertical dimension to horizontal dimension both in Chinese and English. In this mapping, the vertical structures of the spatial concepts are projected onto those of horizontal dimensions. People usually use vertical words like Shang and $U p$ to talk about horizontal positions. For example, in Chinese, we can say:

$$
\begin{aligned}
& \text { 我们下周北上大连. (We will set out up Dalian next week.) } \\
& \text { 他走上前来对我说. (He walked up to me and said.) }
\end{aligned}
$$

From the examples above, we can see that in Chinese, there are elaborations:

\section{Approaching/forward is Shang; Northward is Shang.}

Since the ground is fixed, when an object is approaching us, it appears larger in our eye, so it seems like moving upward to the observer.

According to Shepard \& Hurwitz (1985: 165-166), a lot of evidence shows that early maps were generally oriented in such a way that the upward direction in the map pointed toward some culturally significant or perceptually salient location. Later, with the growing importance of global navigation and the invention of the magnetic compass, the North Pole and the South Pole conferred by the earth's 
rotation become more appropriate and invariant reference points for map drawing. Moreover, since global navigators and map makers were predominantly from the northern hemisphere, the North Pole was favored over the South Pole as the reference point for Shang/ Up. This shows that North is Shang/Up consistent with another conceptual metaphor A more important status is Shang/Up. (Lan Chun 2003: 106)

Specific to Chinese, in ancient China, the south has been considered as desolate places with rather low economy and the north has long been the place that the central government located and the economy and culture in the north are developed compared to the south. As a result, 北上(go up to the north), 南下 (go down to the south) are reflections of people's mind. Although the economy in the south gains rapid development later, the central government is always in the north. Moreover, once the vocabulary comes into the language system, it has a relative fixed feature. Therefore, 北 上 and 南下 are used continuously until now but in their usage, there is no more emotional color in human beings' mind. China has a landform of higher northwest and lower southeast, so going to the west is Shang.
Examples from A Dream of Red Mansions:

1) Approaching is Shang

这门子忙上来请安. (The attendant went down on one knee in salute, then said with a smile.)

黛玉方进入房时, 只见两个人换着一位髸发如银的老母迎上来. (As Tai-yu entered, a silver-haired old lady supported by two maids advanced to meet her.)

2) North and West is Shang

上面五间大正房. (The northern building had five large apartments.)

十九日乃黄道之期, 兄可即买舟西上. (The nineteenth is a good day for traveling. You can hire a boat then and start your journey westward.) II",

According to the data collected in "Table I" and "Table

TABLE I. THE METAPHORICAL EXTENSIONS OF SHANG

\begin{tabular}{|c|c|c|c|c|}
\hline Target domain & $\begin{array}{c}\text { Metaphorical } \\
\text { extensions }\end{array}$ & Number & Percentage out of 310 & Percentage out of 485 \\
\hline States & $\begin{array}{llr}\text { At/towards } & \text { a more } \\
\text { desirable } & \text { state } & \text { is } \\
\text { Shang } & & \end{array}$ & 113 & $36.45 \%$ & $23.30 \%$ \\
\hline Social status & $\begin{array}{l}\text { At/towards a more } \\
\text { important status is } \\
\text { Shang }\end{array}$ & 106 & $34.19 \%$ & $21.86 \%$ \\
\hline Time & $\begin{array}{l}\text { At/towards an earlier } \\
\text { time is Shang }\end{array}$ & 27 & $8.71 \%$ & $5.57 \%$ \\
\hline Quantity & $\begin{array}{l}\text { At/towrards a larger } \\
\text { quantity is Shang }\end{array}$ & 14 & $4.52 \%$ & $2.89 \%$ \\
\hline Extent & $\begin{array}{l}\text { Expreesing an extent } \\
\text { is Shang }\end{array}$ & 50 & $16.13 \%$ & $10.31 \%$ \\
\hline Total & & 310 & $100 \%$ & $63.92 \%$ \\
\hline
\end{tabular}

TABLE II. ELABORATIONS OF SHANG IN SPATIAL SENSE

\begin{tabular}{|c|l|l|l|}
\hline & \multicolumn{1}{|c|}{ Number } & \multicolumn{1}{c|}{ Percentage out of 175 } & \multicolumn{1}{c|}{ Percentage out of 485 } \\
\hline Forward relation & 20 & $11.43 \%$ & $4.12 \%$ \\
\hline Spatial meaning & 155 & $88.57 \%$ & $31.96 \%$ \\
\hline total & 175 & $100 \%$ & $36.08 \%$ \\
\hline
\end{tabular}

\section{Up in English}

After consulting Oxford Advanced Leaner's EnglishChinese Dictionary (Oxford University Press 1997), Collins English Dictionary for Advanced Learners (Harper Collins Publishers 2001), Longman Dictionary of Contemporary English (Foreign Language Teaching and Research Press 2002), meanings of $U p$ can be mainly concluded in the following:

- To or in an upright position e.g. I stood up to ask a question.

- To or in a higher place, e.g. Lift your head up.

- To or in a higher position, condition, degree e.g. Prices are still going up.
So as to be close (to a specified person or thing) e.g. He came up to me and asked the time.

To or in an important place (large city, university, north) e.g. They're up in London. She is going up to Oxford in October. They're moved up north.

Into pieces; apart. E.g. She tore the paper up.

Completion of an action or state. E.g. We ate all the food up.

Happening, going on (especially of something unusually or unpleasant). E.g. What's up?

Be a better state, quality. E.g. Business is on the up-andup state. 
From the above conclusion to the meanings of up, we can see that the meanings of up can be further classified into three groups: vertical sense, metaphorical sense and horizontal sense.

In the following, the metaphorical extensions and the elaborations of up from vertical relations to horizontal relations will be demonstrated.

According to the metaphorical senses, four conceptual metaphors can be abstracted:

- Towards a Larger Quantity is $U p$.

- Towards a More Important Status is $U p$.

- Towards a Latter Time is $U p$.

- Towards a More Desirable State is $U p$.

That is to say, $U p$ can be mapped from vertical domain onto domains of Quantity, Social Status and Hierarchy, Time and States. The realization of this metaphorical mapping is human beings' daily experiences. Quantity, Social Status and Hierarchy, Time and States are all abstract concepts and they are also very important and closely related to our daily life. People map the spatial relations onto those abstract domains so that the abstract concepts will be understood clearer and better.

In the following section, the four abstract concepts making clear by using the spatial word $U p$ will be studied respectively. Since those metaphorical mappings share largely the same experiential grounding as their Chinese counterparts, their experiential mappings will not be repeated anymore. Notes will be taken if there is any distinctive difference.

1) Quantity: The conceptual metaphor of quantity in terms of $U p$ is: Towards a Larger Quantity is Up. This conceptual metaphor can also be called More is Up, which is based on an experiential correlation between adding more of substances to a pile and seeing the level rise. The image schematic structures of $U p$ are mapped onto that of the target domain of quantity.

Examples from Gone with the Wind:

E.g. They're runnin' the assessment up on Tara sky high.

E.g. The Yankees and the scoundrels teamed up with them have got me where they want me.

2) Social Status:The conceptual metaphor of Social Status in terms of Up is: Towards a More Important Status is Up. In this metaphor, the image schematic structures of $U p$ are mapped onto that of the target domain of Social Status and Hierachy. Strength standing for power has been mentioned. Another point needs to be mentioned is that no matter in Chinese and English, the most powerful representatives are emperors or Gods who are up beyond the ordinary people. All the others have to kneel down or bow to show their respect to the power and high status.

Examples from Gone with the Wind:

\section{a) Giving support is UP}

E.g. The Bureau was backed up by the soldiers and the military had issued many and conflicting orders governing the conduct of the conquered.

E.g. The minute Sue got her hands on a little money she'd give herself unendurable airs and never contribute one cent toward the up keep of Tara.

\section{b) A Higher Social Status is Up}

E.g. And after I offered up myself for my country and fought barefooted in the snow at Franklin and got the finest case of dysentery you ever heard of for my pains!

E.g. Then there would have been a stink, for some of them are high up in Washington now.

3) Time: The conceptual metaphor of time in terms of $U p$ is: Towards a Later Time is Up. Spatial concepts are mapped onto the domain of time is widely observed in most cultures. The concept of time is often acquired through that of space. Different from the metaphorical projection to time as At/towards an Earlier Time is Shang, people in English cultural background usually consider problems standing by now and always respect to the future. They think things in the future are bigger and better. Looking from this viewpoint, Towards a Later Time is $U p$ is in their mind. Examples are:

E.g. What have I done with my life, up till now?

E.g. Usually there were a dozen children present, nodding sleepily in their parents' arms, up hours after their normal bedtime.

4) States:The conceptual metaphor of states in terms of $U p$ is: Towards a More Desirable State is Up. In this metaphor, the image schematic structure of $U p$ is mapped onto that of the target domain states. The domain of states can be roughly divided into four sub-domains: mental states of human beings, emotional states of human beings, physical states of human beings or concrete objects, and states of events. In each sub-domain, special metaphorical extensions are observed.

Examples from Gone With the Wind:

a) Mental States: Into virtue, high quality and goodness is Up.

E.g. I've often wondered what it was about you that made me always remember you, for I've known many ladies who were prettier than you and certainly more clever and, I fear, morally more upright and kind.

\section{Into Consciousness is Up.}

E.g. We've never had enough to eat and it's terrible to wake up hungry and go to sleep hungry.

Into a Working State is Up.

E.g. On these occasions Hugh was forced to hunt up new workmen and the mill was late in starting.

Into a More Mature State is Up. 
E.g. And Wade could have nourishing food to fill out his thin cheeks and warm clothes and a governess and afterward go to the university and not grow up barefooted and ignorant like a Cracker.

b) Emotional States:

E.g. "Cheer up," he said, as she tied the bonnet strings.

E.g. "Brace up," said Rhett, and there was a hard, faintly jeering note in his voice. Up.

c) Physical States: Improvement in appearances is

E.g. Young ladies don't dare Yankee sentries to see a prisoner, just for charity's sweet sake, and come all dressed $u p$ in velvet and feathers and seal muffs too.

5) States of Events: Into Existence is Up.

E.g. Fact is, the way the Yankees have framed up that amnesty oath, can't nobody who was somebody before the war vote at all.

\section{Into View is $U p$}

E.g. When at last they reached the town square and the tall white cupola of the city hall loomed up, she made her thanks, climbed down from the wagon and watched the country woman drive off.

\section{Into a Functioning State is Up}

E.g.You run $u p$ and fix me some dry clothes, Mammy

\section{Towards Completeness is Up}

E.g. Stuart halted, too, and the darky boy pulled up a few paces behind them.

\section{Towards a Public State is Up}

\section{Elaborations of Up from Vertical to Horizontal Relations}

As in Chinese, apart from the metaphorical extensions examined in the previous sections, in English, we can also find evidence for the elaboration of $U p$ from vertical relation to horizontal relations, for example, we can say, it must be very cold now up in Canada, and move up, there is plenty of room at the front.

From the above examples, we can see that in English, there are elaborations:

\section{Approaching/Forward is Up.}

E.g. He had hung his coat on a tree limb, for the work was hot, and he stood resting as she came up to him.

E.g. They picked their way across the slippery stepping stones that bridged the mud of Decatur Street and continued up Peachtree, through a thinning crowd.

\section{Northward/Innerland is $U p$}

E.g. I don't know exactly what he'll do but he said he was goin' up North.

E.g. The more sedate and older sections of the South looked down their noses at the up-country Georgians, but here in north Georgia, a lack of the niceties of classical education carried no shame, provided a man was smart in the things that mattered.

\section{E. Summary} IV”,

TABLE III. THE METAPHORICAL EXTENSIONS OF $U P$

\begin{tabular}{|l|l|l|l|l|}
\hline \multicolumn{1}{|c|}{ Target domain } & Metaphorical extensions & Number & Percentage out of 171 & Percentage out of 260 \\
\hline States & $\begin{array}{l}\text { At/towards a more } \\
\text { desirable state is } U p\end{array}$ & 144 & $84.21 \%$ & $55.38 \%$ \\
\hline Social status & $\begin{array}{l}\text { At/towards a more } \\
\text { important status is Up }\end{array}$ & 11 & $6.43 \%$ & $4.23 \%$ \\
\hline Time & $\begin{array}{l}\text { At/towards an earlier time } \\
\text { is } U p\end{array}$ & 4 & $2.34 \%$ & $1.54 \%$ \\
\hline Target domain & Metaphorical extensions & Number & Percentage out of 171 & Percentage out of 260 \\
\hline Quantity & $\begin{array}{l}\text { At/towrards a larger } \\
\text { quantity is } U p\end{array}$ & 12 & $7.02 \%$ & $4.62 \%$ \\
\hline Total & & 171 & $100 \%$ & $65.77 \%$ \\
\hline
\end{tabular}

TABLE IV. Elaborations OF $U P$ IN SPATIAL SENSE

\begin{tabular}{|c|l|l|l|}
\hline & \multicolumn{1}{|c|}{ Number } & \multicolumn{1}{|c|}{ Percentage out of 89 } & \multicolumn{1}{c|}{ Percentage out of 260 } \\
\hline Elaboration & 28 & $31.46 \%$ & $10.77 \%$ \\
\hline Spatial meaning & 61 & $68.54 \%$ & $23.46 \%$ \\
\hline total & 89 & $100 \%$ & $34.23 \%$ \\
\hline
\end{tabular}

In this chapter, a qualitative and quantitative study to the $U p$ sense spatial words between Chinese and English has been done by using Shang and $U p$ as research objects. Shang and $U p$ are selected from the two famous works: A Dream of Red Mansions and Gone with the Wind. Through data analysis, the findings show that the metaphorical extensions of $U p$ are highly frequented in the above two works.

The distribution of the metaphorical extensions and the elaboration from vertical dimension to horizontal dimension of Shang and $U p$ is in the following. 

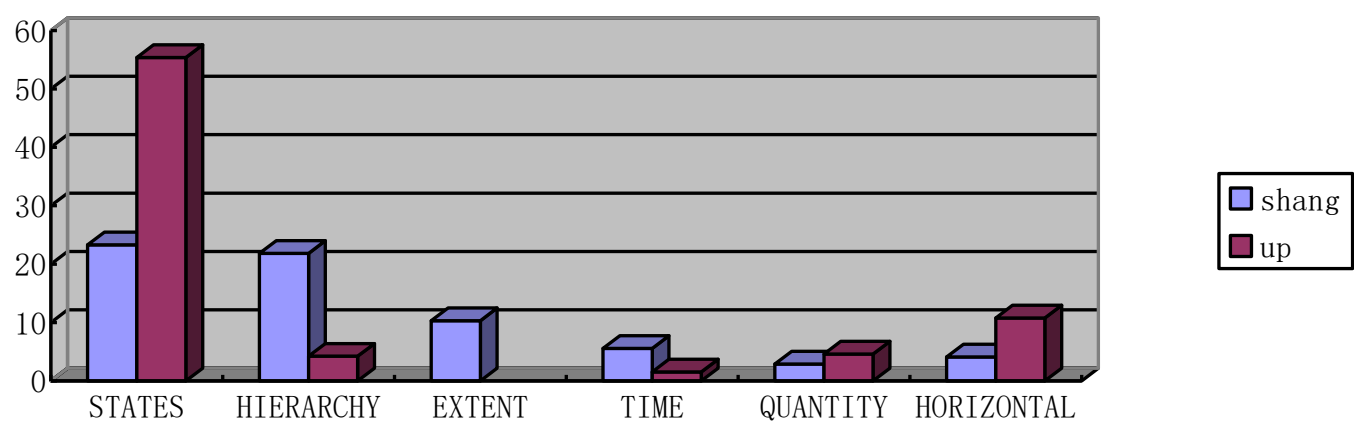

Fig. 1. The distribution of the metaphorical extensions and elaborations of Shang and $U p$. drawn:

From the analysis, the following similarities can be

- Remarkable similarities are drawn out that both Shang and $U p$ are mainly used to structure the same four target domains: Quantity, Social Hierarchy, Time and States.

- With all the four concepts, the metaphorical extension that enjoys highest frequency is States, suggesting that States is a most actively used metaphorical concept.

- Besides the metaphorical extensions, data collection also shows that there is an elaboration from vertical dimension to horizontal dimension.

This agreement between the two languages is a natural result of the experiential grounding of conceptual metaphors. As humans, the Chinese and the English share more or less the same bodily and physical experience, from which more or less the same image-schematic structures will directly emerge and become directly meaningful.

Lakoff (1993:245) claims that "metaphorical mappings vary in universality; some seem to be universal, others are widespread, and some seem to be culture specific". According to the data analysis, the main discrepancy between Shang and $U p$ lies in the target domain of Time and Extent.

- There is a contradiction emerged between the Chinese conceptual metaphor Towards an earlier time is Shang and the English conceptual metaphor Towards a Later Time is Up. Moreover, there is a tendency that $U p$ is rarely used to conceptualize the concept of Time, while Shang plays a more important role in Chinese conceptualization of the concept of Time.

- Chinese Shang can be mapped onto another domain named Extent but English Up does not have the same metaphorical mapping.

\section{CONCLUSION}

\section{A. Major Findings}

The agreement between the two languages is a natural result of the shared experiential grounding of conceptual metaphors. As human beings, Chinese and English share more or less the same bodily and physical experience. Therefore, almost the same image-schematic structures are emerged. Similarities between Chinese and English $U p$ sense spatial metaphors are:

- The two concepts are mainly used to structure the same four abstract target domains, namely Quantity, State, Time and Social Status;

- With all the four non-spatial target domains, the metaphorical extension that enjoys highest frequency is States ;

- It has also been noticed that the two concepts can be elaborated from a vertical dimension to a horizontal dimension.

On the other hand, since bodily experience cannot be separated from the specific, physical, social and cultural environments where it takes place, it is also expected that there should be variations among the conceptual metaphorical systems of different cultures. Data analysis shows that there are also discrepancies between English and Chinese spatial metaphors in Up and Shang in the domain of Time and Extent.

In the domain of Time, there is contradiction between Chinese and English as in Chinese At/towards an Earlier Time is Shang, but in English Towards a Later Time is Up. The contradiction comes from different cognition towards time by Chinese and English people. Apparently, Chinese conceive time as fixed locations arranged along a vertical landscape and an earlier time is above a later time. Human beings are moving downwards along the vertical landscape towards future. They can go upwards to revisit an earlier time. Therefore, past is up. Different from the Chinese cognition, English tend to believe that time is moving upward from past towards present (and future). Therefore, a later time is above an earlier time (Lan Chun, 2003). 
From the examples in this paper, we can see that there are two conditions in Chinese 'Shang' structure. One is to express an attached relation, correspondent to 'on' in English like "on the desk"; and the other is to express a non-attached relation correspondent to 'at, on, in, above, over' in English like "an expert at English/ playing football"; "a report/ book/ comment on English"; "a book rich in ideas, poor/low in a certain subject". Therefore, the most prominent difference in Extent concept between English and Chinese is that Chinese pays special attention on vertical relations and looks down upon 'inside/outside' relations, while English strengthens the overall dimensions and the most typical example is 'at, on, in'. As 'at, on, in' refer that the contact between the trajector and landmark is respectively a point, a line or surface, and a body or a field, 'an expert at English' emphasizes that the expert is accomplished to a certain specific major or technique. 'An expert on English' has a wider meaning, refers to professional knowledge related to English. The meaning of 'an expert in English' is even wider referring to the English field. In fact, all these uses are extended when mapping the spatial dimension onto an abstract extent.

Therefore, in expressing Extent by using metaphorical mapping, Chinese and English use the same method that is to project the specific spatial dimension onto the abstract Extent. However, there is a significant difference in their expressing structure. Chinese use 'noun + Shang' to express both attached relation and non-attached relation, while English select different prepositions to express this relation according to judging the dimension of the contact surface. On this aspect, this phenomenon reflects that in the two concepts of position and extent, Chinese tend to be more general while English tend to be more specific.

\section{B. Implications}

The investigation of the metaphorical extensions of spatial metaphor theoretically supports Lakoff's conceptual metaphor theory. Metaphor is a way to investigate human mind through language analysis. Metaphor is one of the main mechanisms which enable us to understand abstract concepts and to carry out abstract reasoning. In addition, the present study provides evidences for some cognitive linguists' prediction that there may indeed exist a universal spatial metaphorical system.

In application, this research is helpful for language teaching and learning because metaphorical theory has positive guiding effect and applicable value for language teaching and learning. Language teachers can use metaphorical theory to explain the changing and developing process of language meaning and interactive relations among lexical words. Meanwhile, as this is a contrastive study between English and Chinese, it is also useful for translation.

\section{Limitations and Further Studies}

This paper is a research about spatial metaphors within the framework of cognitive linguistics. After the analysis to two most frequently used spatial words Shang and $U p$, similarities as well as differences in spatial metaphors between English and Chinese come into our view. However, Shang in Chinese expressions like 晚上 (evening) 上当 (subject to fraud) are not included in the present study and remained a problem needs to be further studied. Moreover, as the present study only made an analysis to one spatial concept $U p$ between English and Chinese, although efforts were made to maintain its validity and reliability, there are still limitations in its breadth and depth. If more spatial concepts and more languages will be under research and analysis, the researching findings will be more valuable.

\section{REFERENCES}

[1] Akhundov, Murad D. Conceptions of Space and Time. Trans. By Charles Rouge. Cambridge, Mass.: MIT Press, 1986.

[2] Caballero, R. Re-viewing space: figurative language in archetects' assessment of built space. Application of Cognitive Linguistics 2. Berlin/New York: Mouton de Gruyter, 2006.

[3] Cameron, L., \& Deignan, A. "The Emergence of Metaphor in Discourse". Applied Linguistics, 27,pp. 671-690, 2006.

[4] Chilton, Paul. Metaphor in Mental Representations of Space, Time and Society: The Cognitive Linguistic Approach. Berlin/New York: Mouton de Gruyter, 2006.

[5] Johnson, M. "Philosophical Implications of Cognitive Semantics. Cognitive Linguistics" 3-4, pp. 345-66, 1992.

[6] Lakoff, G. \& Johnson, M. Metaphors We Live By. Chicago: The University of Chicago Press, 1980.

[7] Lakoff, G. The Contemporary Theory of Metaphor. Cambridge: Cambridge University Press, 1993.

[8] Lakoff, G. "What is a Conceptual System?" In Willis F Overton and David S. Palermo (eds.), pp. 41-90, 1994.

[9] Lakoff, G. \& Mark Johnson. Philosophy in the Flesh---The Embodied Mind and its Challenge to Western Thought. New York: Basic Books, 1999.

[10] Lan Chun. Cognitive Linguistics and Metaphor Studies. Beijing: Foreign Language Teaching and Research Press, 2003.

[11] Langacker, Ronald W. Foundations of Cognitive Grammar: Theoretical Prerequisites. Stanford: Standford University Press, 1987.

[12] Shepard, Roger N., \& S. Hurwitz, Upward direction, mental rotation, and discrimination of left and right turns in maps. In Pinker (ed.) Visual Cognition. London: MIT Press, 1985.

[13] Turner, Mark. "Aspects of the Invariance Hypothesis". Cognitive Linguistics 1, pp. 247-255, 1990.

[14] Turner, Mark. "Language is a virus". Poetics Today 13, pp. 725-736, 1992.

[15] Turner, Mark. An Image-schematic constraint on metaphor. In Geiger \& Rudzka-Ostyn (eds.) Conceptualizations and Mental Processing in Language. Berlin: Mouton de Gruyter, 1993.

[16] Tyler, A. Applying Cognitive Linguistics to Learning the Semantics of English to, for and at: An Experimental Investigation. Vigo International Journal of Applied Linguistics, vol. 8, pp. 181-205, 2011.

[17] Tyler, A.,\& Evans, V. The Semantics of English Prepositions: Spatial Sciences, Embodied Meaning, and Cognition. Cambridge: Cambridge University Press, 2003.

[18] Ungere, F., \& Schmid, H. J. An Introduction to Cognitive Linguistics. Beijing: Foreign Language Teaching and Research Press, 2001.

[19] Wang Yin. Cognitive Linguistics. Shanghai: Shanghai Foreign Language Education Press, 2007.

[20] Zhao Yanfang. An Introduction to Cognitive Linguistics. Shanghai: Shanghai Foreign Language Education Press, 2001. 